\title{
A review on saponins from medicinal plants: chemistry, isolation, and determination
}

\begin{abstract}
Saponin isolated from medicinal plants is a naturally occurring bioorganic molecule with high molecular weight and its aglycone (water non-soluble part) nucleus having 27 to 30 carbon atoms besides one or two sugar moieties (water soluble part) containing at least 6 or 12 carbon atoms respectively. The complexity of saponin chemistry maybe considered as a gap for many scientists and researchers to understand the relationship between the chemical structure and its medical or pharmaceutical behavior. Recently, the increase in demand of saponin applications was observed due to various biological, medicinal, and pharmaceutical actions. Therefore, this present review article provides detailed information about the chemistry of saponin, especially triterpenoid saponin. Classifications, chemical structure, the possible traditional isolation ways, qualitative, and quantitative determination of saponins were included exclusively. Examples of mono and bidesmosidic structure of oleanolic acid and hederagenin also outlined. Structural differences between triterpenoid, steroid, and alkaloid glycosides were summarized according to their atoms, rings, and functional groups.
\end{abstract}

Keywords: Saponine, chemistry, isolation, medicinal plants, extraction, determination, triterpenoid, steroidal saponin, alkaloidal saponin
Volume 7 Issue 4 - 2019

\author{
Maher Mohamed Abed El Aziz, Aziza Said \\ Ashour, Al Sadek Gomha Melad \\ Chemistry Department, Faculty of Education, University of \\ Tripoli, Libya
}

Correspondence: Aziza Said Ashour, University of Tripoli, Libya,Tel 00218924369783,Email hrshr152@gmail.com

Received: January 25, 2019 | Published: February 22, 2019

\section{Introduction}

It has been estimated that out of 4,22,000 flowering plants reported from the world, more than 50,000 are used for medicinal purposed. Since ancient times, bioactive medicinal plants are used in traditional or folk medicine for the treatment of various diseases. Recently using of phytochemicals is considered to be safer and congenial to the biology of the human body. Medicinal plants are the main source for the preparation and extraction of various modern drugs and pharmaceuticals like saponins. Signs of progress of Phytochemistry have been supported enormously by the rapid development and accumulation of chemical methods of screening of various medicinal plants for particular biochemical usage. The pharmaceutical and medicinal values of the applied medicinal plants are in the bioactive phytochemical constituents that produce specific physiological action on the human body. Some of the most important bioactive constituents are saponins, flavonoids, and alkaloids. Triterpenoid saponins are surface active glycosides of triterpenes that possess a wide, biologically active group of terpenoids and include a large chemical diversity of secondary metabolites with more than different 100 carbon skeletons identified from terrestrial, marine living organisms, and medicinal plants. ${ }^{2}$ Triterpenoids as a saponin have its own characteristics like cause hemolysis of red blood cells (RBC's), form persistent froth if shaken with water, and it is soluble in water, alcohol and a mixture of both. These naturally occurring compounds form the backbone of modern medicine or drugs. Saponins are a class of bioorganic compounds found in particular abundance in the plant kingdom. More specifically, they are naturally occurring glycosides described by the soap-like foaming, and consequently, they produce foams when shaken in aqueous solutions. Structurally saponins are having one or more hydrophilic glycoside sugar moieties combined with a lipophilic triterpene molecule. ${ }^{3}$ Literature shows that saponins exhibit a biological role and medicinal properties such as hemolytic factor ${ }^{4}$ anti-inflammatory, ${ }^{5}$ antibacterial, ${ }^{6}$ antifungal, ${ }^{7}$ antiviral, insecticidal $^{9}$, anticancer, ${ }^{10}$ cytotoxic $^{11}$ and molluscicidal action. ${ }^{12}$ In addition, saponins are reported to exhibit cholesterol-lowering action in animals and human. ${ }^{13,14}$ Waheed et al. ${ }^{15}$ isolated a novel steroidal saponin glycoside from Fagonia indica that can induce cell-selective apoptosis or necrosis in cancer cells. Saponins were considered as a starting precursor for the semi-synthesis of steroidal drugs in the pharmaceutical industry. Sheng et al. ${ }^{16}$ reviewed the clinical significance of triterpenoid saponins in the prevention and treatment of metabolic and vascular disease. The above medicinal researches and applications reflect the increasing of the interest of saponins as a bionatural source material, but understanding of the relationship between the chemistry of saponins and its medical action is not easy task for many chemists, physicians, and researchers. Due to the complexity, importance, and interferences of the chemistry of saponin, the main purpose of this review article is giving detailed information about (1) the classification of saponin, (2) the chemical structure of various types of saponins and its functional groups, (3) examples for mono and didesmosidic triterpenoid saponins, (4) ordinary and soxhlet extraction methods in the laboratory, and finally (5) qualitative, and quantitative determination of saponins.

\section{Chemistry of saponins}

Saponins are naturally occurring bioorganic compounds having at least one glycosidic linkage (C-O-sugar bond) at $\mathrm{C}-3$ between aglycone and a sugar chain. Hydrolysis of saponin molecule produces two portions, aglycone and a sugar moiety. Isolated amorphous solid saponins have a high molecular weight, and containing 27 to 30 carbon atoms in the non-saccharide portion. Figures 1-3 show the chemical structure of saponins in details including the following two chemically different partitions:

\section{Partition (A): Non-saccharide}

Non-saccharide portion (the hydrocarbon skeleton part without 
sugar chain) called genin, sapogenin, or aglycone. Depending on the type of sapogenin present, the saponins can be divided into three major classes: ${ }^{17}$

1) Triterpenoid glycosides (Figure 3B): This type of saponins is the most widely distributed in the plant kingdom. The term triterpene is meaning three monoterpenes ( 10 carbon atoms) of 30 carbon atoms distributed as six isoprene molecules. Figure $3 \mathrm{~A} \& 3 \mathrm{~B}$ shows that triterpene molecule and triterpenoid glycosides are pentacyclic compounds having 30 carbon atoms, and no spiro-carbon atoms (one carbon common in two rings). Triterpenoid glycosides contain 4 oxygen atoms and are normally having one hydroxyl group $(\mathrm{OH})$ at $\mathrm{C}-3$ and carboxyl group $(-\mathrm{COOH})$ at $\mathrm{C}-28$. One oxygen atom presents in the molecule as ether-linked oxygen at $\mathrm{C}-3$, the two oxygen atoms present as ester-linked oxygen at $\mathrm{C}-28$, whereas, the remaining oxygen atom presents as a non-attached alcoholic group $\left(-\mathrm{CH}_{2}-\right.$ $\mathrm{OH})$ at $\mathrm{C}-24$. As shown in Figure $3 \mathrm{E} \& 3 \mathrm{~F}$, and according to the number of sugar moieties attached to the aglycone nucleus, triterpenoid saponin can be classified into two types ${ }^{18,19}$ monodesmosidic and didesmosidic. Mono and didesmosidic structure of oleanolic acid and hederagenin as triterpenoid saponin were presented in Table 1. Monodesmosidic triterpenoid glycosides have a single sugar chain, normally attached at C-3. Bidesmosidic triterpenoid glycosides have two sugar chains, often with one attached through an ether linkage at $\mathrm{C}-3$ and the other either attached through an ester linkage at C-28 or through an ether linkage at C-24.

2) Steroid glycosides Figure 3C: Steroid glycosides are modified triterpenoids with the structure of a tetracyclic six-membered rings and bicyclic five-membered rings containing 27 carbon atoms. Steroid glycosides have two hetero rings, one of both is furan ring and the other is a pyran ring. One spiro-carbon atom is common between the two hetero rings (furanose and pyranose rings). Figure 2 shows an example of steroid glycoside ${ }^{20}$ which have one sugar chain at C-3 through an ether linkage, and it less distributed in nature comparing to triterpenoid saponins.
Steroidal saponins used mainly as precursors for the partial synthesis of sex hormones.

3) Alkaloid glycosides Figure 3D: It's the third class of nonsaccharide portion of saponins. Alkaloid glycosides are having steroid-like structure, but alkaloid glycosides have piperidine ring (six-membered ring containing $\mathrm{N}$-atom) instead of pyranose ring (six-membered ring containing $\mathrm{O}$-atom) in steroid glycosides. Structural differences between triterpenoid, steroid, and alkaloid glycosides were summarized in Table 2, and Figures 3B-3D, from which it can be noticed that both steroid and alkaloid aglycone have no carboxylic group (-COOH), and triterpenoid saponins has no spiro-carbon atom. ${ }^{21}$

4) Partition (B): Saccharide moiety has a variety of pentoses (furanose ring) or hexoses (pyranose ring) sugars. It may be Dextro (D) or Leavo (L) isomers of $\alpha$, and $\beta$ anomers (conformation at $\mathrm{C}-1$ of the sugar). Simply the two saponin portions (aglycone and sugar moieties) can be designated as shown in Table 2. From this table, it was found that oleanolic acid (Ole) and hederagenin (Hed) are two triterpenoid aglycones attached to a variety of sugar moieties forming mono, di, tri, and tetra-saccharide saponin structures. Rhamnose, arabinose, xylose, glucose, and ribose are the most hexoses sugar present in saponins. According to the above mentioned classes and Figures $1 \& 3$, saponins can be categorized into three types, triterpenoidal, steroidal, and alkaloidal saponins. The three categories of saponins can be formed and symbolized by the following equations:

Triterpen aglycone +2 sugar moieties $\stackrel{\text { give }}{\rightarrow}$ bidesmosidic triterpenoid saponins Triterpen aglycone +1 sugar moiety $\stackrel{\text { give }}{\rightarrow}$ monodsmosidic triterpenoid saponins Steroid aglycone +1 sugar moiety $\stackrel{\text { give }}{\rightarrow}$ steroidal saponins Alkaloid aglycone +1 sugar moiety $\stackrel{\text { give }}{\rightarrow}$ alkaloid saponins

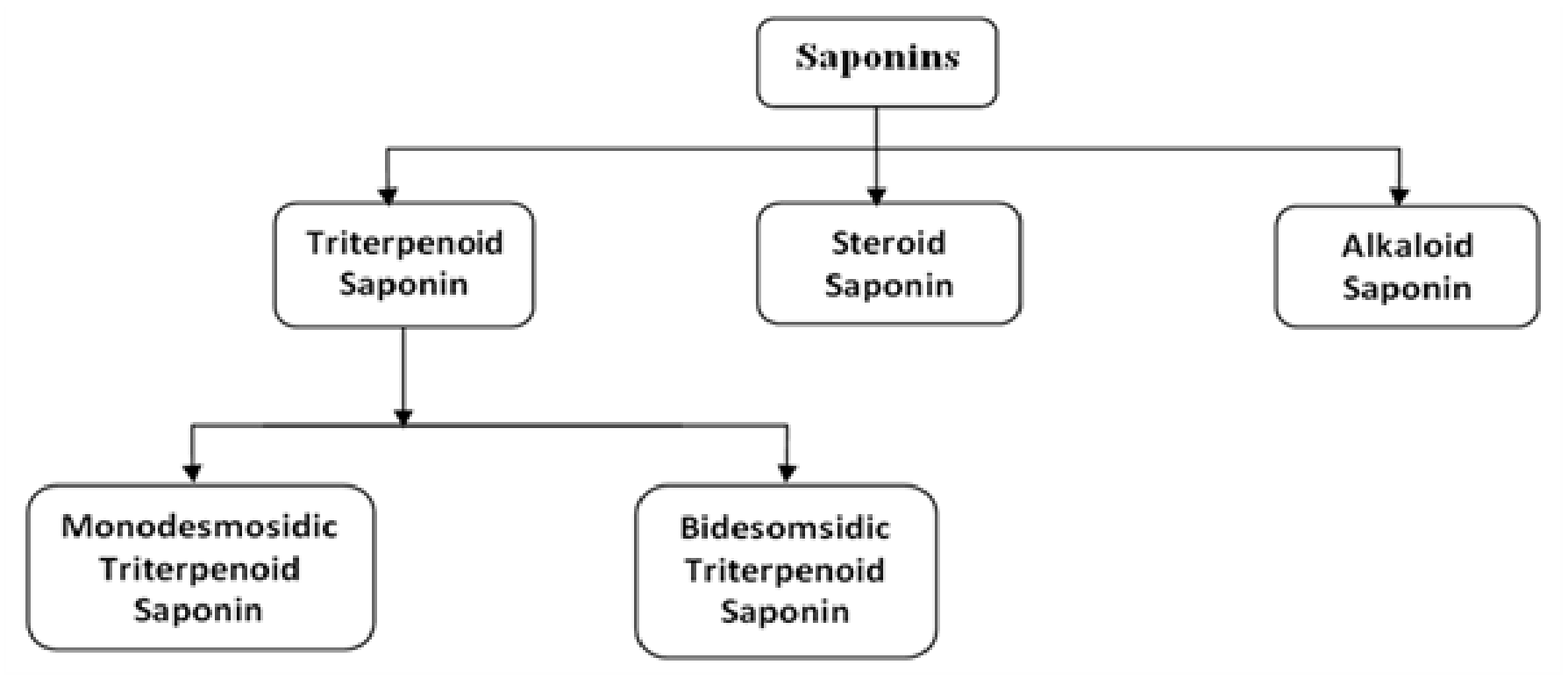

Figure I Categories of saponins. 


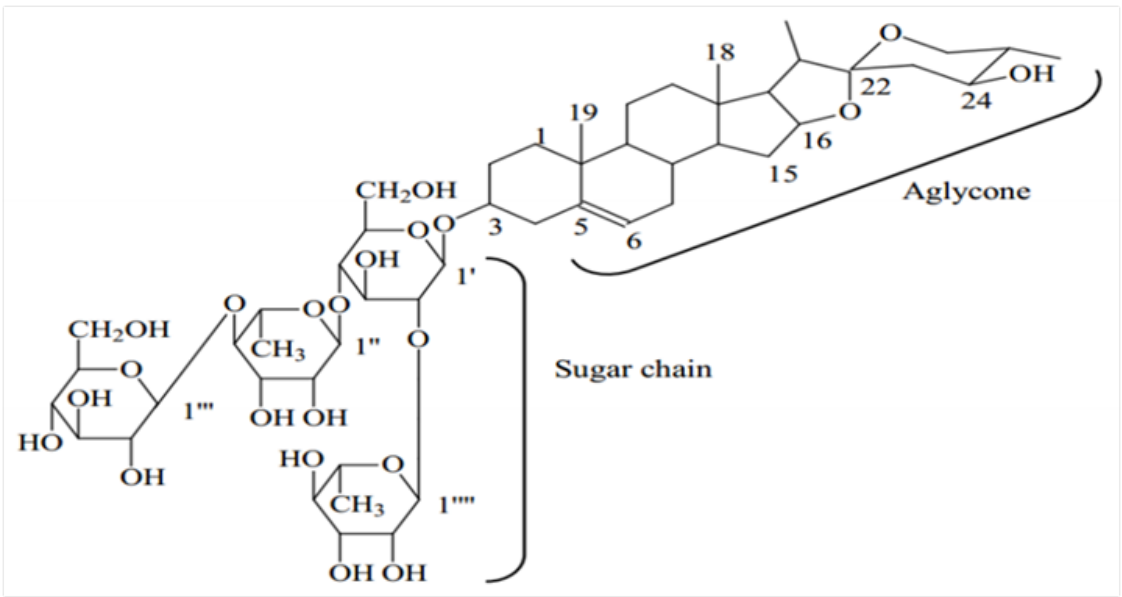

Figure 2 The chemical Structure of steroid saponin. ${ }^{20}$

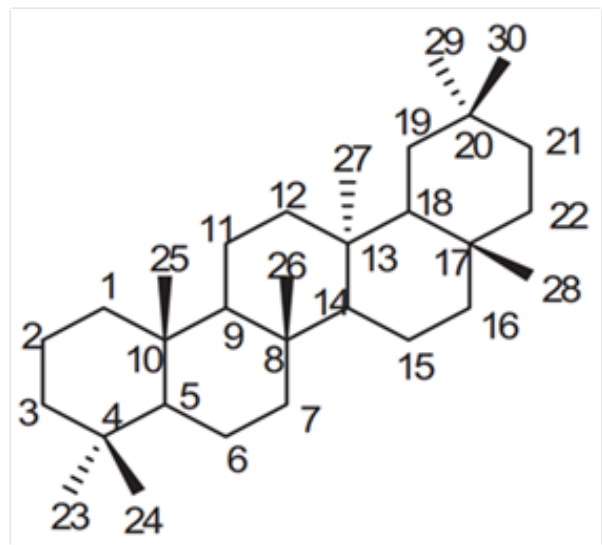

A) Carbon Skeleton of Triterpene (30C). ${ }^{18}$

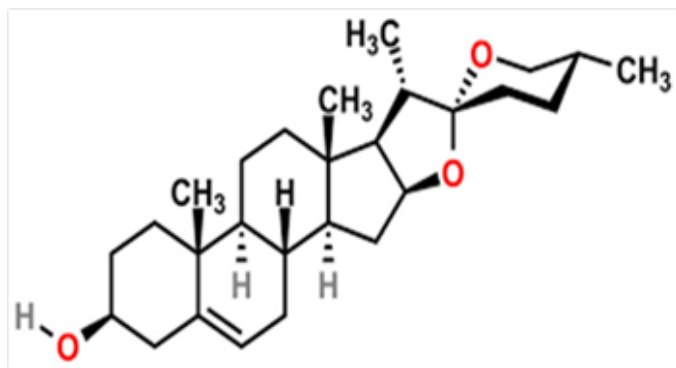

C) Steroid Glycosides (27C). ${ }^{21}$

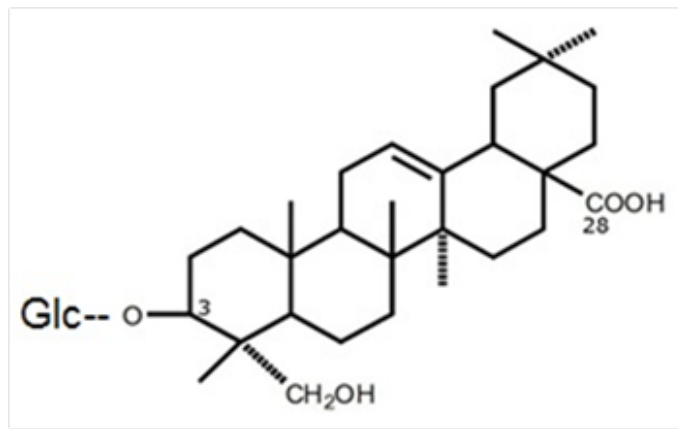

E) Monodesmosidic Triterpenoid Saponin. ${ }^{18}$

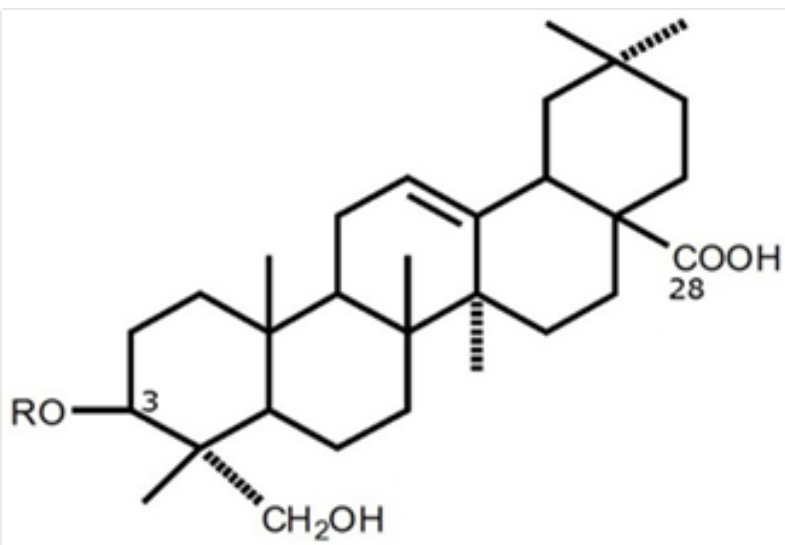

B)Triterpenoid Glycosides (30C). ${ }^{21}$

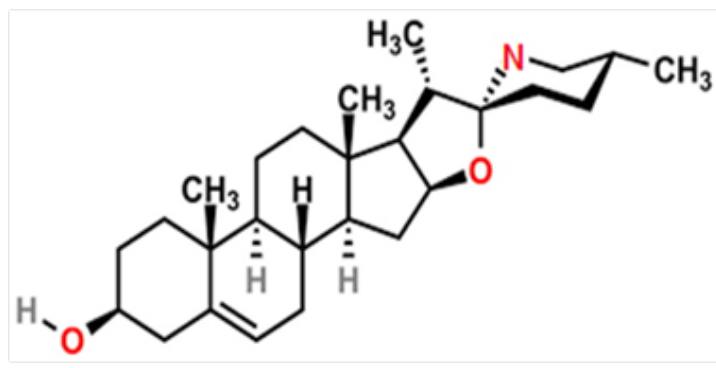

D) Alkaloid Glycosides (27C). ${ }^{21}$

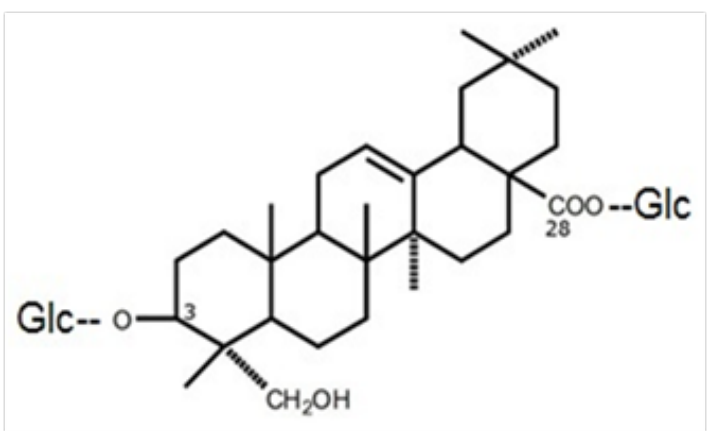

F) Bidesomsidic Triterpenoid Saponin. ${ }^{18}$

Figure 3 Classification of aglycone and triterpenoid saponins. 
Table I Examples for mono and didesmosidic triterpenoid saponins

\begin{tabular}{|c|c|c|c|}
\hline Saponin structure & Aglycone & Type of sugar moiety & Type of Glycoside \\
\hline Rha .Ara.Ole & & Disaccharide & Monodesmosidic \\
\hline Xyl. Rha .Ara . Ole & Triterpenoid: & Trisaccharide & Monodesmosidic \\
\hline Glu . Rib . Rha .Ara . Ole & Ole: Oleanolic acid & Tetrasaccharide & Monodesmosidic \\
\hline Glu. Glu. Ole. Glu & & Di \& monosaccharide & Bidesmosidic \\
\hline Are. Hed & & Monosaccharide & Monodesmosidic \\
\hline Glu .Ara .Hed & Triterpenoid & Disaccharide & Monodesmosidic \\
\hline Xyl . Rha .Ara.Hed & Hed: Hederagenin & Trisaccharide & Monodesmosidic \\
\hline Glu .Xyl . Rha .Ara . Hed & & Tetrasaccharide & Monodesmosidic \\
\hline Ara . Hed . Glu . Glu . Rha & & Mono \& trisaccharide & Bidesmosidic \\
\hline Rha .Ara. Hed. Glu. Glu . Rha & & Di \& trisaccharide & Bidesmosidic \\
\hline Rha: $\alpha$-L-rhamnopyranozyl & \multicolumn{2}{|c|}{ Ara: $\alpha$-L-arabinopyranozyl } & Xyl: $\beta$-D-xylopyranozyl \\
\hline Glu: $\beta$-D-glucopyranozyl & \multicolumn{2}{|c|}{ Rib: $\beta$-D-ribopyranozyl } & \\
\hline
\end{tabular}

Table 2 Structural differences between triterpenoid, steroid, and alkaloid glycosides

\begin{tabular}{|c|c|c|c|c|}
\hline Differences & & Triterpenoid glycosides & Steroid glycosides & Alkaloid glycosides \\
\hline \multirow{5}{*}{ Atoms } & No. of carbon atoms & 30 & 27 & 27 \\
\hline & No of spiro-carbon atoms & 0 & 1 & I \\
\hline & No. of oxygen atoms & 4 & 3 & 2 \\
\hline & No. of Nitrogen atoms & 0 & 0 & I \\
\hline & Six-membered rings & 5 & 4 & 4 \\
\hline \multirow{3}{*}{ Rings } & Five-membered rings & 0 & 2 & 2 \\
\hline & Total number of rings & 5 & 6 & 6 \\
\hline & Hetero rings & 0 & 2 & 2 \\
\hline \multirow{3}{*}{ Functional groups } & No. of $-\mathrm{COOH}$ group & I & 0 & 0 \\
\hline & No. of $-\mathrm{OH}$ group & 2 & 1 & I \\
\hline & $\mathrm{C}=\mathrm{C}$ double bond & I & I & I \\
\hline
\end{tabular}

\section{Extraction and isolation of saponin}

Due to the increase in public awareness of preventative health care, an intensive review on the recent advances in extraction of a bioactive compound from medicinal plants have been reported in references..$^{22,23}$ Almost kinds of literature explain three different techniques for the extraction of saponins. Ordinary extraction and soxhlet extractor are well-known extraction methods, while modern techniques like ultrasound-assisted extraction, microwave-assisted extraction, and accelerated solvent extraction methods are still in advances and enhancements. According to Choon $\mathrm{YC}^{24}$ maceration, reflux, and soxhlet extraction represent about $\sim 60 \%$ of the employed techniques in the extraction of saponins from plant materials. Modern extraction processes represent about $\sim 30 \%$, while subsequent extraction method represents about $10 \%$ of the employed techniques. Therefore, attention will be paid to the traditional extraction techniques in our present review.

\section{Ordinary extraction}

The extraction of saponins by maceration is the famous method using the ordinary solvent-like alcohols and n-butanol. It is a solidliquid interface extraction where saponin's compounds inside the plant material can easily extract by immersion or soaking the plant materials in a suitable specific solvent for a period of time with or without stirring or shaking. ${ }^{25}$ The polarity of the solvent, temperature, maceration time, solubility of saponins and its effective diffusion in the liquid phase are the main operational variables affecting the efficiency of the ordinary extraction process. Normally, the polar saponins dissolve in polar solvents, and the nonpolar compounds dissolve in nonpolar solvents. ${ }^{26}$ The rate of diffusion of saponins into the liquid phase depends upon the rate of mass transfer of a solute from the plant material to the solvent ${ }^{25}$ The concentration gradient between the solid and liquid phases is the driving force of diffusion of saponins into solvent. ${ }^{25}$ The ordinary maceration technique is very simple and does not need a sophisticated experimental setup. Ethanol $\mathrm{C}_{2} \mathrm{H}_{5} \mathrm{OH}$, methanol $\mathrm{CH}_{3} \mathrm{OH}$, acetone $\mathrm{CH}_{3} \mathrm{COCH}_{3}$, ethyl acetate $\mathrm{CH}_{3} \mathrm{COOC}_{2} \mathrm{H}_{5}$, dichloro methane $\mathrm{CH}_{2} \mathrm{Cl}_{2}$, and a mixture of solvents are the ordinary solvents used for the extraction of saponins from plant material, but ethanol (50-98\%) and n-butanol $\mathrm{CH}_{3}\left(\mathrm{CH}_{2}\right)_{2} \mathrm{CH}_{2} \mathrm{OH}$ are the commonly used solvent. Occasionally the time of maceration varied 
from few hours to few days (3d), 6weeks are the longest recorded time, and 30 minutes are the shortest recorded time of ordinary extraction. Maceration of plant materials by organic solvents may be accelerated or facilitated by heat, shaking and/or magnetic stirring. The temperature of extraction varies from ambient to the boiling point of the chosen solvent, and the amount of extracted materials also varies from a few grams to few kilograms. The amounts of isolated saponins are a function of time of extraction, temperature, shaking, and the amount of original material. The longer extraction time, the higher temperature, and the heavier extracted mass with shaking the more amount of isolated saponin will be, and vice versa. The amount of used solvent or extractant does not specify adequately and varied from few milliliters to few tens of liters. Ordinary column chromatography with silica gel stationary phase and an organic solvent as a mobile phase consumes more and more solvents than static maceration process. Various saponins with different chemical structures can be extracted by maceration from the wild, desert, and cultivated plants with various species. After maceration, the alcoholic crude extract of plant materials then evaporated to obtain a more concentrated saponin containing solution. This solution may dilute with water, and directly subjected to a solvent extraction process using n-butanol and separating funnel. Finally, n-butanol easily removed using rotatory evaporator under vacuum, and the remaining saponin residue stays in the round-bottomed flask. The dry residual saponin material can be fractionated and identified using one or more techniques e.g. column chromatography, Sephadex, thin layer chromatography (TLC), and/ or high-performance liquid chromatography (HPLC). The most commonly employed solvent system for TLC are chloroform - glacial acetic acid - methanol - water (60:32:12:8) and ethyl acetate - formic acid - glacial acetic acid - water (100:11:11:26). ${ }^{27}$ Methanol water system $\left(\mathrm{MeOH}-\mathrm{H}_{2} \mathrm{O}\right)$ is the common solvent system used with HPLC. ${ }^{28}$ The extraction and identification of saponin from the plant material are not easy and described as a tedious process.

\section{Soxhlet extraction}

Distillation process of plant material by soxhlet is faster than the ordinary maceration process because it involves heating the organic solvent to its boiling point and then returning the condensed vapors to the original flask after passing through the plant tissue in the condenser, so the extraction process takes place via the direct contact between the plant tissue and the hot fumes of the solvent. After a considerable extraction time, the colorless solvent becomes green dark solution due to the mass transfer into solvent. ${ }^{29}$ Then the solution was dried by rotary evaporator to dryness to obtain the dry crude extract of the plant which suspended in water, extracted by n-butanol and fractionated as mentioned above. Still soxhlet extraction affected greatly by the polarity of the solvent, extraction time, and the extraction temperature. Ordinary maceration process is static extraction, but soxhlet is dynamic extraction due to the circulation of solvent during extraction. The powder of the plant may initially defatted with $60-$ $80^{\circ} \mathrm{C}$ petroleum ether or n-hexane statically or dynamically until the fatty components had been removed before the final extraction.

\section{Qualitative determination of saponins}

Saponin tests were carried out on the plant materials using standard procedures as described in references. ${ }^{30-32}$ The common methods of screening for the presence of saponins in the plant material depends on the three major characteristics of saponin (1) the chemical characteristics, and the formation of stable foam with shaking, ${ }^{33}$ (2) the hemolytic action of saponin on blood, ${ }^{34}$ and (3) the surface-active properties of saponin. ${ }^{35}$ The occurrence of saponins can be determined and confirmed qualitatively in the laboratory by different saponin tests as follows in details:

1) Standard foam test: $3 g$ of each dry plant powder were weighed and extracted with $300 \mathrm{ml}$ of hot distilled water in a beaker. After filtration, the aqueous extracts were cooled, stirred and stored at $4^{\circ} \mathrm{C}$ in an automated refrigerator for $24 \mathrm{~h}$. About $5 \mathrm{ml}$ of the plant extract was transferred into a test tube and diluted with $5 \mathrm{ml}$ of distilled water. The mixture was shaken vigorously for 2 minutes. Persistent appearance of foam lasting for at least 15 minutes or the forming of an emulsion when olive oil was added confirmed the presence of saponins.

2) Wet foam test: The test solution was diluted by water and shaken vigorously for 1-2min, a stable foamy lather appeared in the top of the test tube of the sample.

3) Dry foam test: About $\approx 0.5$ gram of crude powder of the plant was shaken with $5 \mathrm{ml}$ distilled water in a test tube and warmed in a water bath, the stable persistent froth, was mixed with 3 drops of olive oil and shaken vigorously. The formation of emulsion indicates the presence of saponins.

4) Foam test for fresh samples: About $\approx 2$ gram of fresh plant sample (leaves) was add to $20 \mathrm{ml}$ distilled water $(\mathrm{w} / \mathrm{w}=1: 10)$, mixed together by electrical mixer, the mixture was filtered, the filtrate was concentrated by evaporation in a water bath to half of the original volume, then transferred into a test tube. The stable persistent froth was mixed with 3 drops of olive oil and shaken vigorously than observed for the formation of the emulsion, indicate the presence of saponins.

\section{Quantitative determination of saponins}

In this method, saponins are traditionally extracted into water/ ethanol mixtures, after which the alcohol is removed by evaporation and the saponins extracted from the water phase into n-butanol. According to the reference, ${ }^{36,37}$ saponin can be determined quantitatively by taking the dry powder of the plant sample weighing about $5 \mathrm{~g}$ and poured into $200 \mathrm{ml}$ of $20 \%$ ethanol solution. The suspension was heated over a hot water bath for $3-4 \mathrm{~h}$ with continuous stirring at about $55-60^{\circ} \mathrm{C}$. The mixture was filtered and the solid residue of the plant powder was re-extracted with another $200 \mathrm{ml}$ of $20 \%$ ethanol solution. The two combined solutions were evaporated over a water bath at about 80$90^{\circ} \mathrm{C}$ to reduce the volume to about $40 \mathrm{ml}$. The concentrated solution was transferred into a $250 \mathrm{ml}$ separating funnel and $20 \mathrm{ml}$ of diethyl ether was added and shaken vigorously to remove impurities from the original solution. The aqueous layer was recovered for another extraction while the ether layer with impurities was discarded. The purification process was repeated again after that $60 \mathrm{ml}$ of n-butanol was subsequently poured twice and the combined n-butanol solutions $(120 \mathrm{ml})$ were washed twice with $20 \mathrm{ml}$ of $5 \%$ aqueous sodium chloride. The remaining aqueous solution was transferred to a dried pre-weighed porcelain crucible and dried in a drying oven at $60^{\circ} \mathrm{C}$ to a constant weight. The remaining residue is the saponin product, which can be calculated by the equation:

$$
\text { Total saponin contents, }(\%)=\frac{\text { weight of the saponin residue }}{\text { weight of the original plant material }} \times 100
$$

To increase the isolated saponin contents, a large quantity of plant material will be used. The process seems to be efficient, but having many of technical and environmental disadvantages, like using three 
organic solvents (alcohol, ether, and n-butanol) with remarkable amounts, the need of heating, the need of drying, and timeconsuming. Another method for the determination of total saponin content was reported ${ }^{30}$ in which the dry aerial parts of the plant $(5.0 \mathrm{~g})$ were defatted twice with petroleum ether $\left(60-80^{\circ} \mathrm{C}\right)(2 \times 50 \mathrm{ml})$, and alcoholic solution $(75 \%, 150 \mathrm{ml})$ was added to the defatted phase. Then, the mixture was refluxed at $70^{\circ} \mathrm{C}$ for four hours, the extract solution filtered and evaporated at $40-50^{\circ} \mathrm{C}$ in rotavapor. The dry residue was dissolved by a suitable amount of distilled water, and extracted triplicate with $\mathrm{n}$-butanol $(3 \times 40 \mathrm{ml})$. The combined n-butanol solution was evaporated at $90^{\circ} \mathrm{C}$ using rotavapor to dryness, and the yield of saponin calculated according to equation (1).

\section{Conclusion}

This review shows that saponin has two main parts: the aglycone and a sugar moiety. Saponin with one sugar moiety was known as monodesmosidic, but with two sugar moieties was called bidesmosidic. According to the number of carbon atoms, the number of oxygen and nitrogen present in the molecule, aglycone or genin, or sapogenin itself was categorized into triterpenoid, steroid, and alkaloid glycosides. Maceration in organic solvent and Soxhlet are the main traditional isolation ways of saponins. The presence of saponin in the plant material may be confirmed using dry or wet test depending on the foam formation characteristics. Determination of total saponin contents can be proceeding via consecutive solvent extraction by n-butanol.

\section{Acknowledgments}

None.

\section{Conflicts of interest}

Authors declare there is no conflict of interest.

\section{References}

1. Vincken JP, Heng L, de Groot A, et al. Saponins, classification and occurrence in the plant kingdom. Phytochemistry. 2007;68(3):275-297.

2. Mahato SB, Nandy AK, Roy G. Triterpenoids. Phytochemistry. 1992;31(7):2199-2249.

3. Vasudeva RN, Sukhendu BG ,Pushpalatha B, et al. Triterpenoid saponins:a review on biosynthesis, applications and mechanism of their action. Int J Pharm Pharm Sci. 2015;7(1):24-28.

4. Hassan SM, Haq AU, Byr JA, et al. Haemolytic and antimicrobial activities of saponin-rich extracts from guar meal. Food Chemistry. 2010;119:600-605.

5. Just MJ, Recio MC, Giner RM, et al. Anti-inflammatory activity of unusual lupane saponins from Bupleurum fruticescens. Planta Medica. 1998;64(5):404-407.

6. Sparg SG, Light ME, van Staden J. Biological activities and distribution of plant saponins. J of Ethnopharmacology. 2004;94(2-3):219-243.

7. Sindambiwe JB, Calomme M, Geerts S, et al. Evaluation of biological activities of triterpenoid saponins from Maesa lanceolata. J Nat Prod. 1998;61(5):585-590.

8. Simões CMO, Amoros M, Girre L. Mechanism of antiviral activity of triterpenoid saponins. Phytother Res. 1999;13(4):323-328.

9. Ellen De Geyter, Ellen Lambert, Danny Geelen, et al. Novel advances with plant saponins as natural insecticides to control pest insects. Pest Technology. 2007;1(2):96-105.
10. Cheng TC, Lu JF, Wang JS, et al. Antiproliferation effect and apoptosis mechanism of prostate cancer cell PC -3 by flavonoids and saponins prepared from Gynostemma pentaphyllum. J Agric Food Chem. 2011;59(20):11319-11329.

11. Armelle T Mbaveng, Ndontsa BL, Kuete V, et al. A naturally occurring triterpene saponin ardisiacrispin B displayed cytotoxic effects in multifactorial drug resistant cancer cells viaferroptotic and apoptotic cell death. Phytomedicine. 2018;43(1):78-85.

12. Abdel Gawad MM, El Sayed MM, Abdel Hameed ES. Molluscicidal steroidal saponins and lipid content of Agave decipiens. Fitoterapia. 1999;70(4):371-381.

13. Oboh HA, Omofoma CO. The effects of heat treated lima beans (Phaseolus lunatus) on plasma lipids in hypercholesterolemic rats. Pak J Nutr. 2008;7(5):636-639.

14. Eskandar Moghimipour, Somayeh Handali. Saponin:properties, methods of evaluation and applications. Annual Research \& Review in Biology. 2015;5(3):207-220.

15. Waheed A, Barker J, Barton SJ, et al. A novel steroidal saponin glycoside from Fagonia indica induces cell-selective apoptosis or necrosis in cancer cells. Eur J Pharm Sci. 2012;47(2):464-473.

16. Sheng H, Sun H. Synthesis, biology and clinical significance of pentacyclic triterpenes:a multi-target approach to prevention and treatment of metabolic and vascular diseases. Nat Prod Rep. 2011;28(3):543-593.

17. Hostettmann K, Marston A. Saponins. UK: Cambridge University Press; 1995.

18. Eva Madland. Extraction, isolation and structure elucidation of saponins from Herniaria incana. MSc thesis, Norwegian University of Science and Technology. 2013

19. Guclu Ustundag O, Mazza G. Saponins:properties, applications and processing. Crit Rev Food Sci Nutr. 2007;47(3):231-258.

20. Chaieb I. Saponins as insecticides: a review. Tunis J Plant Prot. 2010;5:39-50.

21. Abed El Aziz MM, Ashour AS, Madbouly HA, et al. Investigations on green preparation of heavy metal saponin complexes. $J$ Water Environ. Nanotechnol. 2017;2(2):103-111.

22. Azmir J, Zaidula ISM, Rahman MM, et al. Techniques for extraction of bioactive compounds from plant materials:a review. Journal of Food Engineering. 2013;117(4):426-436.

23. Wang L, Weller, CL. Recent advances in extraction of nutraceuticals from plants. Trends in Food Science and Technology. 2006;17(6):300-312.

24. Cheok CY, Karim Salman HA, Sulaiman R. Extraction and quantification of saponins:a review. Food Res Int. 2014;59:16-40.

25. Takeuchi TM, CG Pereira, ME Braga, et al. Low pressure solvent extraction (solid-liquid extraction, micro wave assisted, and ultrasound assisted) from condimentary plants. Boca Raton: CRC Press; 2009, p. $151-158$.

26. Reichardt C, Welton T. Solvents and solvent effects in organic chemistry. 4th edn. Weinheim: Wiley Online Library; 2011.

27. Gangwal A. Extraction estimation and thin layer chromatography of saponins:a review. International journal of pharmaceutical and chemical sciences. 2013;2(3):1366-1368.

28. Wieslaw Oleszek, Anna Stochmal. High performance liquid chromatography of triterpenes (including saponins). In: Monika Waksmundzka-Hajnos, Joseph Sherma, High Performance Liquid Chromatography in Phytochemical Analysis. UK: Taylor \& Francis Group; 2010:633-651 
29. Bart, HJ. Extraction of natural products from plants - an introduction. Industrial scale natural products extraction. 1st edn, Weinheim: WileyVCH; 2011.

30. Kareru PG, Keriko JM, Gachanja AN, et al. Direct detection of triterpenoid saponins in medicinal plants. Afr J Trad CAM. 2008;5(1):56-60.

31. Harborne JB. Phytochemical methods - a guide to techniques of plant analysis. 3rd edn. Netherlands: Springer Ltd; 2005. p. 302.

32. Tukiran. Phytochemical analysis of some plants In Indonesia. Journal of Biology, Agriculture and Healthcare. 2013;3(4):6-10.

33. Ncube B, Ngunge VNP, Finnie JF, et al. A comparative study of the antimicrobial and phytochemical properties between outdoor grown and micropropagated Tulbaghia violacea Harv. plants. $J$ of Ethnopharmacology. 2011;134(3):775-780.
34. Bissinger R, Paola Modicano, Kousi Alzoubi, et al. Effect of saponin on erythrocytes. International journal of hematology. 2014;100(1):51-59.

35. Gonzalez Valdez LS, et al. Surfactant properties of the saponins of Agave durangensis, application on arsenic removal. International Journal of Engineering and Applied Sciences. 2013;4(2):87-94.

36. Ukpabi Chibueze, Akubugwo EI Agbafor K, et al. Phytochemical and heavy metal composition of Telfairia occidential and Talinium triangulare grown in Aba Nigeria and environmental health implications. American Journal of Biochemistry. 2013;3(3):67-73.

37. Kumar Ashwani, Bhardwaj Ashish. Comparative, qualitative, quantitative chemotypic characterization among north Indian Tribulus terrestris. IRJP. 2012;3(6):212-218. 